\section{Free genome databases finally defeat Celera}

Emma Marris, Washington

It's official: the genome wars are over. Celera Genomics, the company that raced against the public Human Genome Project to be the first to sequence our genetic blueprint, has announced that it will stop selling genomic information.

Celera was established in 1998 with the goal of commercializing access to genome-sequence information. Its bold plan to sequence the human genome in just a couple of years spur red on the public project, which made its data available free of charge. In June 2000 , the two rivals declared the race a tie.

With so much genome data publidy available, the company realized as early as 2002 that the promised profits were not going to materialize. Its high-profile president Craig Venter, who had championed the sequencing effort, resigned to pursue other genomics interests.

Celera Genomics, based in Rockville, Maryland, will continue as a pharmaceutical company, working closely with its sibling Celera Diagnostics. Its drug-discovery efforts will build on some still-proprietary information, induding a collection of single-nudeotide mutations from 39 humans and a chimpanzee. "It has become a different company in many ways," says Kathy Ordoñez, Celera's current president.

The last of the genomic information service, called the Celera Discovery System, will close by the end of June. All Celera's genomic data, including more recent mouse and rat sequences, will be made available in the public databases of the US National Center for

Biotechnology Information in Bethesda, Maryland, in July.

The newly free human sequence will probably not be a great boon to researchers, as it is largely replicated by data from the Human Genome Project. But the rat and mouse sequences should be in more demand. "They will be quite useful because they are doing different strains," says Francis Collins, director of US National Human Genome Research Institute in Bethesda.

Collins, who led the Human Genome Project through the genome wars, calls the data release a "victory for the scientific community". Now he's speaking words of peace: "They have done a generous thing here and should be getting a lot of credit."

\title{
Arctic trends scrutinized as chilly winter destroys ozone
}

Quirin Schiermeier, Munich

The biggest ozone losses ever recorded over the Arctic have got scientists arguing over whether global warming is to blame. If there is a link, the spectre of an Arctic ozone hole looms.

Researchers announced their preliminary results, from measurements taken between January and March, at last week's meeting of the European Geosciences Union in Vienna. Atmospheric scientist Markus Rex, of the Alfred Wegener Institute of Polar and Marine Research in Potsdam, Germany, and his colleagues reported that after this winter's unusually low Arctic temperatures, ozone losses are greater than any seen before (see graph).

The ozone layer shields the Earth from harmful ultraviolet radiation, but it is being eaten away by chlorofluorocarbons (CFCs). The existence of an ozone hole over the Antarctic was first reported exactly 20 years ago (Farman, J. C., Gardiner, B. G. \& Shanklin, J. D. Nature 315, 207-210; 1985); and production of CFCs was phased out by the Montreal Protocol just two years later. However, remnants of these long-lived chemicals are likely to linger in the atmosphere for at least another 50 years.

Ozone loss in the Arctic is less severe than in the colder Antarctic, and seems more dependent on temperature variation. Certain clouds in the stratosphere provide surfaces on which CFC decay products are converted into forms that destroy ozone - but the clouds only form at temperatures below $-80^{\circ} \mathrm{C}$.

The past Arctic winter was particularly cold and in some areas more than half of the ozone molecules were destroyed. By early spring, ozone-depleted air had drifted southwards through large parts of northern and central Europe.

Increasing levels of greenhouse gases are known to have a cooling effect on the stratosphere, because heat is locked near the sur-

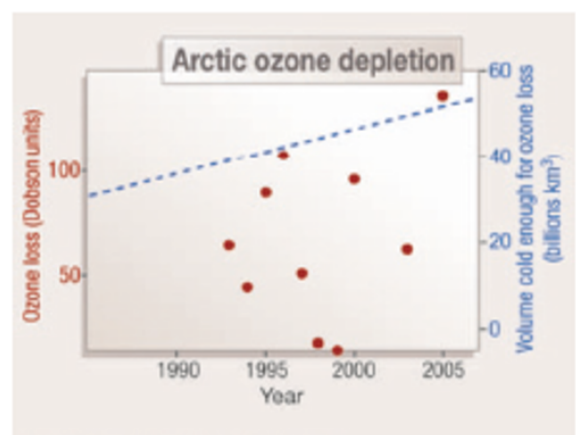

Norrel owone bevek 300 Dobeon units

face. ${ }^{\alpha}$ Over the past 40 years, we have seen a fourfold increase in the area cold enough for polar stratospheric clouds," says Rex. He and his colleagues believe this year's losses are a sign that colder winters could lead to an Arctic ozone hole in the next two decades.

But other scientists are sceptical. ${ }^{\alpha}$ This has been a very interesting Arctic year, temperature-wise and ozone-wise," says Susan Solomon, an atmospheric chemist and cochair of an Intergovernmental Panel on Climate Change working group. ${ }^{\alpha}$ But any attempt to link ozone loss to greenhouse gases is extremely speculative."

Solomon argues that the temperature drop this winter was far too large to be explained by greenhouse cooling, and that natural fluctuations in meteorological conditions probably far outweigh greenhouse effects. "You can't just look at radiation,"she says, "the fact that the two preceding winters were very warm should give us pause."

Rex acknowledges that there are still manyunknowns, although he says we should not have to wait too long for answers. His results are part of SCOUT-O3, a $€ 15$-million (\$20-million) collaboration involving over 100 scientists from 19 countries. The project aims at understanding the links between ozone, greenhouse gases and the dimate system as a whole - it will run for four more years.

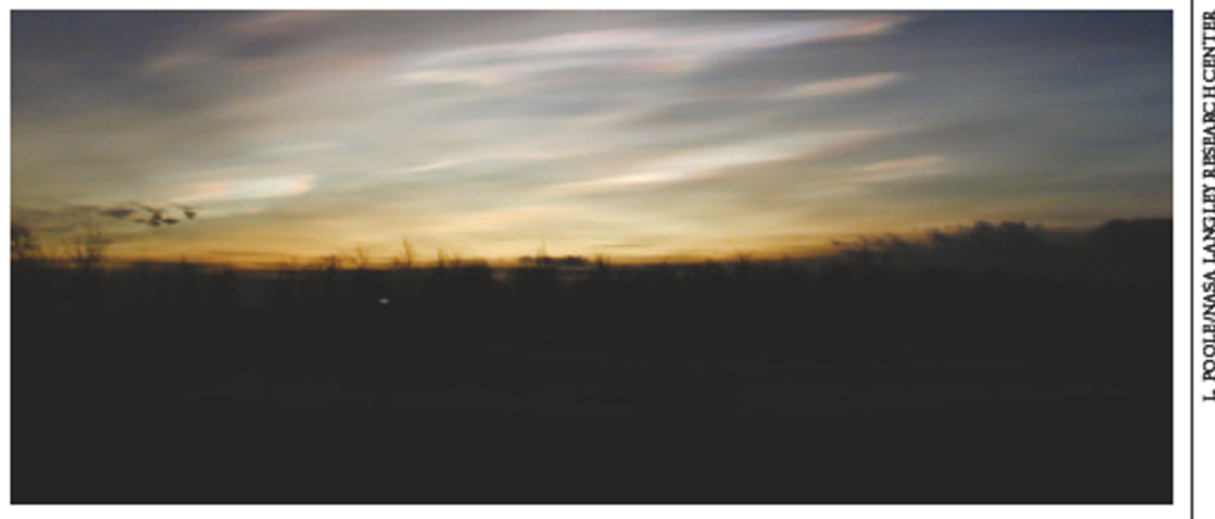

Long shadows: these polar douds need low temperatures to form, but can wreak havoc on Arctic ozone. 